\title{
Interdisciplinary Global Health Forum: Conference Report
}

\section{Quinn J.. ${ }^{1}$, Rajaratnam V.2 , Smejkal P. ${ }^{3}$, Bencko V. ${ }^{1}$}

${ }^{1}$ Institute of Hygiene and Epidemiology, First Faculty of Medicine, Charles University in Prague and General University Hospital in Prague, Prague, Czech Republic; ${ }^{2}$ First Faculty of Medicine, Charles University in Prague, Prague, Czech Republic; ${ }^{3}$ Department of Infectious and Tropical Diseases, First Faculty of Medicine, Charles University in Prague and Hospital Bulovka, Prague, Czech Republic

Received June 25, 2012; Accepted April 8, 2013.

Key words: Health security - Fragile and failed states - Prevention Immunization - Global health - Conference reports

Abstract: In spring of 2012, students and staff at the First Faculty of Medicine at Charles University in Prague invited distinguished public health stakeholders and experts to engage in a Global Health Forum. The forum lasted an afternoon, was academically and clinically engaging and offered students and medical faculty a venue to discuss the most pressing global public health concerns. Main outcomes from the forum included describing outstanding public issues in public health policy and prevention, infectious disease and public health systems raised by the speakers, stakeholders and attendees. One major result of this forum is the establishment of the Prague Center for Global Health - an interdepartmental and interdisciplinary research collaborative to further the discussion and much needed field and academic research in global public health. The Prague Center for Global Health will include multiple international research centers and main function and results will include new courses at the university, publications based on best practices and research and a venue to learn, share and create in the academic space.

Mailing Address: John Quinn, MD., MPH., Institute of Hygiene and Epidemiology, First Faculty of Medicine, Charles University in Prague and General University Hospital in Prague, Studničkova 7, 12800 Prague 2, Czech Republic; Mobile Phone: +420 608246 032; e-mail: John.quinn@If1.cuni.cz 


\section{Introduction}

The Global Health Forum conference conducted on May 3rd, 2012 in the Cori Lecture Hall was organized by students Venu Rajaratnam and John Quinn and supported by the Institute of Hygiene and Epidemiology, First Faculty of Medicine, Charles University in Prague. The focus of the conference was to engage global public health leaders to discuss public health trends and vulnerabilities in the new global normal. Topics of invited speakers included neglected disease, vaccination programs in the developing world, and health and food security in times of economic crisis, trans-border health in war, conflict and medical tourism and aid international humanitarian program successes and failures.

The Interdisciplinary Global Health Forum was the culmination and encouraged by present research by the Institute of Hygiene and Epidemiology on Failed States and Health Security and on vulnerabilities of Health and Food Security worldwide. The Institute of Hygiene and Epidemiology is also engaged with activities related to health effects of human exposure to different occupational and environmental risk factors, occupational health and medical services, hospital hygiene and nosocomial infections, disease prevention and treatment of tobacco dependence and tobacco control.

The Global Health Forum was a cross pollination of these research topics with students, faculty and staff and global public health experts and key stakeholders. There were four speakers and a question and answer session that included participation from faculty, staff and students and concluded with recommendations and needed outcomes for global public health. The major outcome and prime product of the Global Health Forum was the establishment of the collaborative research institute, the Prague Center for Global Health.

\section{Background}

Medical students, doctors and researchers worldwide face new challenges in the study and practice of medicine in the new global normal of financial crisis, globalization and endemic infectious and non-infectious disease. As new and young doctors enter the global workforce, many challenges offering a standard of care, realizing and understanding medical risk and being able to communicate and work within patient cultural norms define not only a few of the major challenges to global public health, but highlight the dynamic nature of the interdisciplinary endeavour that is medicine (Varmus et al., 2003; Rudan, 2012). Ever more frequently, there are more connections between doctors working in the developed world and both patients and diseases from the least developed and resource poor nations. The interconnectedness of health and healthcare, across sectors and across medical specialties is highlighted everyday through the challenges of patient care in a globalized world and new resource limitations in an ongoing global financial crisis. For medical students and young doctors to better understand these connections and engage with public health experts and better understand the dynamic state of 
public health and patient care, continuous and multidisciplinary engagement must increase.

The main theme of this university-sponsored event was to address global public health trends and vulnerabilities in the new global normal. This new global normal involves global financial crisis, increased people movement across borders and populations prone to low intensity conflict with high levels of violence and a dearth of healthcare and medical personnel planet-wide; the most recent of which includes the slaughter of innocent civilians in Syria and the consequent humanitarian crisis pouring into neighbouring states (Quinn et al., 2011).

The speakers and topics of the invited presenters included:

1. Dora Tomíčková, MD., Senior lecturer in infectious diseases, First Faculty of Medicine and representative of Doctors Without Borders (MSF), "HIVIAIDS treatment in the developing world";

2. Kateřina Pospíšilová, MD., PhD., Medical Director Vaccines Central and South East Europe, GlaxoSmithKline (GSK) "Value of vaccines in the developing and developed world";

3. Serap Ersoy, Republic of Turkey, First Counsellor, Deputy Head of Mission, "Medical and Healthcare Tourism";

4. Alan J. Smith, Keynote speaker, US Foreign Service Officer, US Embassy Prague, "US Support for Global Health".

These topics of neglected disease, vaccination programs in the developing world, health and food security in times of economic crisis, infectious disease and aid program successes and failures help to educate and clarify the challenges that new and still training doctors face. The Global Health Forum was conducted in an apolitical manner, was free of charge, free of sponsorship and the organizers and supporters promoted no political or governmental agenda. All participants discussed all views, arguments and positions in an academic, respectful and balanced manner. The Forum officially commenced with Vice-Dean Prof. Otomar Kittnar in an address to all participants to appreciate and realize that medicine is indeed a global endeavour.

\section{Topics discussed}

Each speaker was invited and offered 15-30 minutes to discuss their recent research and work in global public health. Dr. Tomíčková, senior lecturer in infectious diseases, discussed her field work and breath of relating HIVIAIDS. Her presentation sparked much discussion and questions from the student and faculty audience about standards of care for HIVIAIDS treatment in the developing world. In detail, Dr. Tomíčková's presentation focused on global HIV projects that included voluntary HIV testing, HIV prophylaxis and treatment of opportunistic infections and starting combination antiretroviral therapy (cART) throughout the globe, especially 
in resource poor and developing nations. Her main conclusions were that there are good possibilities to help people living with HIVIAIDS, even in resource poor countries. Pandemic HIVIAIDS is a major health emergency in global public health.

Dr. Pospišilová, present Medical Director at GlaxoSmithKline (GSK), offered unfettered access to explaining the link of private research and true global health affects in the public sphere. Her presentation was very detailed as to the clear understanding in the literature with immunization, vaccination and the relationship of prevention of disease and its role in global health and health security for populations. The potential of a malaria vaccine, and other neglected disease vaccination and advanced treatments currently in the research pipeline at GSK, were of key interest by all participants and may engender a sea change in public health policy and programming.

Her presentation highlighted the need for increased global access and cover of vulnerable and at risk populations to that of preventable disease and its role to human security, growth and development. Vaccine and immunization programs have offered huge leaps in medical advancement in recent history. GSK markets over 30 vaccines worldwide to prevent potentially life-threatening or crippling illnesses such as hepatitis A, hepatitis B, diphtheria, tetanus, whooping cough, measles, mumps, rubella, polio, typhoid, influenza and bacterial meningitis. She concluded that the strength of the GSK vaccine pipeline would provide opportunities to consistently deliver new vaccines. One such vaccine under research is aimed at malaria and is still in preliminary phases of development but offers much promise for the hundreds of millions afflicted with malaria annually. According to the World Malaria Report 2011, there were roughly 216 million cases of malaria with an estimated 655,000 deaths in 2010 with most deaths occurring among children living in Africa (WHO, 2011).

Counselor Ersoy, focused on trans-border health and healthcare tourism into Turkey. Counselor Ersoy also discussed the growing humanitarian crisis in Syria and its overflow effects in the border regions throughout Turkey. As healthcare costs rise significantly across the globe, and patient mobility becomes less restricted across borders in some regions, patients are seeking cheaper alternatives for equal access to affordable healthcare and to guarantee health security. It was noted that Turkey offers a very cost-effective option for patients wishing to travel for elective and non-elective health procedures and offers high European standards in medicine at fractions the cost of home country therapy. She commented that more and more patients are choosing Turkey for healthcare tourism for its geographical travel ease and rich culture.

Discussion highlighted that presently there is a crisis in some Turkish border zones with Syria as violence increases and nearly 60,000 civilians are said to have perished. She lamented that there were no discussions set for any collaborative efforts to help with the displaced persons being received at Turkish border regions, but Turkeys' presence in NATO offers a venue for future mutual aid and support 
with such crisis if it becomes necessary or requested - there is presently much NATO movement and discussion of intervention or a response to the humanitarian crisis. Estimates vary but the number of civilian and non-combatants deaths in Syria's conflict, and the number of internally and externally displaced, have risen sharply since violence began in Syria in spring 2011.

Finally, Officer Smith from the United States Embassy in Prague highlighted the forum as the keynote speaker. His talk entitled, "US Support for Global Health," was informative and very inclusive on US global health programming worldwide. Mr. Smith is a US Foreign Service Officer, currently serving in the Economic Section of the US Embassy in Prague where he covers science and technology, energy, and macroeconomic issues. His comments on the United States Agency for International Development (USAID) and many other global health actors helped bring into focus the very broad need for global health programming from the developed to the developing world across disciplines.

Officer Smith highlighted that twenty US Government agencies have global health programs in a total of 80 countries, and that the Global Health Initiative under President Obama coordinates these programs. All of these programs are designed around seven core principles, such as focusing on women and gender equality, promoting research and innovation, building sustainability, and improving metrics and evaluation. Under the Obama Administration, the US Government has achieved an 84 percent increase in the number of people receiving AIDS treatment, now reaching more than 3.2 million people. Officer Smith continued to note that the US also treats more than 1 million smear-positive cases of TB each year and that USAID is a leading stakeholder in global public health in collaboration with several non-governmental organizations and universities in the US, such as Mayo Clinic and Johns Hopkins University, among many others. His presentation included a case study in Bangladesh of a network of more than 300 clinics operating on an able-to-pay model after local partners receive training in business and financial management with great success. Officer Smith concluded that future programming by US agencies can help guide development globally and there are many global health issues that require renewed support by multiple actors and stakeholders.

\section{Forum outcomes}

Two major outcomes of the Global Health Forum are the highlighted options for medical student engagement in global health and the need for the establishment of the Prague Center for Global Health. Many students found it interesting to hear about vaccine programming and the health economics issues associated with vaccine research such as prioritization, as well as, to hear about the potential of a new malaria vaccine and other neglected tropical diseases currently still under research. Many students also found the ability for intermittent volunteer and clinical work with such humanitarian agencies as Doctors Without Borders (MSF) to be of special interest for future global health work throughout student and graduate careers. 
It was concluded that the need for more university sponsored events and information resources for clinical, policy and basic public health opportunities to be conveyed to students were highlighted and discussed. Students can indeed play a role in the complex issues posed by the least developed countries of the world, and as medical students many feel the need to contribute accordingly and require resources to do so. The cross-pollination of academic research and practical disciplines engenders innovation, new ideas and growth. As students, young doctors and young researchers in medicine, the need for an interdisciplinary global public health research collaborative found in the Prague Center for Global Health is needed in order to challenge old paradigms and bring about new ideas for both new and old global problems through evidenced-based and creative solutions.

This Prague Center will be a collaborative between the Institute of Hygiene and Epidemiology, other faculty departments and the Institute for International Affairs in Prague. This collaborative will be not only a networking forum for research collaboration, it will fundamentally enhance communication, data, results and conclusions of all departments and projects related to public health and allow experts and students to comingle in the academic space and publish, create and provide insight to global health troubles.

\section{Summary}

Medical students, faculty, staff and researchers face new challenges in the study and practice of medicine and public health in the new global normal, which is ever more frequently defined by recurrent financial crisis, globalization winners and losers and the spread and consequences to endemic infectious and noninfectious disease. As new and young doctors enter the global workforce, many challenges of offering a standard of care, realizing and understanding medical risk and being able to communicate and work within patient cultural norms defines only a few of the major challenges to global public health. Ever more frequently, there are more connections between doctors working in the developed world and both patients and disease from the developing and resource poor nations. The interconnectedness of health and healthcare, across sectors and across medical specialties is highlighted everyday with patient care. For medical students and young doctors to understand these connections and engage with further resources to better understand the dynamic state of public health is very apparent.

The main goal of this university-sponsored event was to address global public health trends and vulnerabilities in the new global normal. The main outcomes were not only spirited debate and discussion in public health, but were also the creation of the Prague Center for Global Health. The authors sincerely hope such debate, research, analysis and focus can also lead to evidenced-based policy and clinical solutions for those who have no access to stability or health security and healthcare infrastructure. 
134) Prague Medical Report / Vol. 114 (2013) No. 2, p. 128-134

\section{References}

Quinn, J., Hnilicova, H., Mensah, E., Bencko, V. (2011) Iraqi physician brain drain in prolonged conflict. N. Iraqi J. Med. 7(1), 88-98.

Rudan, I. (2012) Global health research priorities: mobilizing the developing world. Public Health 126(3), 237-240.

Varmus, H., Klausner, R., Zerhouni, E., Acharya, T., Daar, A. S., Singer, P. A. (2003) Public Health. Grand Challenges in Global Health. Science 302(5644), 398-399.

World Health Organization (WHO) (2011) World Malaria Report 2011. WHO Press, Geneva. 